\title{
Mitochondrial protective mechanism of simvastatin protects against amyloid $\beta$ peptide-induced injury in SH-SY5Y cells
}

\author{
YUNZI LI ${ }^{1,2}$, QIAN LIU ${ }^{2}$, JING SUN $^{1}$, JIN WANG $^{1}$, XINFENG LIU ${ }^{2 *}$ and JING GAO ${ }^{1 *}$ \\ ${ }^{1}$ School of Pharmacy, Jiangsu University, Zhenjiang, Jiangsu 212013; ${ }^{2}$ Department of Neurology, Jinling Hospital, \\ Medical School of Nanjing University, Nanjing, Jiangsu 210002, P.R. China
}

Received August 11, 2016; Accepted January 25, 2018

DOI: $10.3892 /$ ijmm.2018.3456

\begin{abstract}
Mitochondrial dysfunction is implicated in the pathology of neuronal damage during Alzheimer's disease (AD). Previous studies suggest that simvastatin (SV) ameliorates amyloid $\beta(\mathrm{A} \beta)$-mediated cognitive impairment in $\mathrm{AD}$ patients and transgenic mice; however, the mechanisms remain unknown. To investigate the potential mechanisms by which SV protects against AD neurotoxicity, the present study used a series of cellular and molecular assays to analyze the effects of SV in an in vitro model of $A \beta_{1-42}$-induced injury. The results demonstrated that SV protected against $\mathrm{A} \beta_{1-42}$-induced SH-SY5Y cell injury by inhibiting the release of cytochrome $c$ from the mitochondria to the cytoplasm, and reducing the production of intracellular reactive oxygen species. In addition, SV downregulated cleaved-caspase-3 protein levels, increased the ratio of $\mathrm{B}$ cell lymphoma 2 (Bcl-2) to Bcl-2-associated $\mathrm{X}$ protein, and increased the protein levels of peroxisome proliferator-activated receptor $\gamma$ coactivator- $1 \alpha$ in the $A \beta_{1-42}$-treated cells. Furthermore, $\mathrm{SV}$ increased the mitochondrial membrane potential and adenosine triphosphate levels, and enhanced the cell respiratory function and mitochondrial mass of the cells. In conclusion, the
\end{abstract}

Correspondence to: Professor Jing Gao, School of Pharmacy, Jiangsu University, 301 Xuefu Road, Zhenjiang, Jiangsu 212013, P.R. China

E-mail: jinggao@ujs.edu.cn

Professor Xinfeng Liu, Department of Neurology, Jinling Hospital, Medical School of Nanjing University, 305 East Zhongshan Road, Nanjing, Jiangsu 210002, P.R. China

E-mail: xfliu2@vip.163.com

${ }^{*}$ Contributed equally

Abbreviations: AD, Alzheimer's disease; A $\beta$, amyloid $\beta$ peptide; SV, simvastatin; MTT, 3-(4,5-dimethylthiazol-2-yl)-2,5-diphenyltetrazolium bromide; ROS, reactive oxygen species; DCFH-DA, dichlorofluorescin diacetate; JC-1, 5,5',6,6'-tetrachloro-1,1',3,3'-tetraethylbenzimidazolcarbocyanine iodide; MMP, mitochondrial membrane potential; Cyt $c$, cytochrome $c$; PGC-1, peroxisome proliferator-activated receptor $\gamma$ coactivator-1

Key words: simvastatin, amyloid- $\beta$ peptide, Alzheimer's disease, mitochondrial, apoptosis present study revealed that SV protected SH-SY5Y cells against $\mathrm{A} \beta_{1-42}$-induced injury through regulating the mitochondrial apoptosis pathway and mitochondrial function.

\section{Introduction}

Alzheimer's disease (AD) is a prevalent type of dementia, the morbidity of which is increasing in the elderly population. Today, 47 million people live with dementia worldwide. This number is projected to increase to more than 131 million by 2050, as populations age (1). AD is a severe neurodegenerative disorder involving cognitive and motor decline, which progresses from mild cognitive impairment affecting the memory, concentration and speech, to late-stage cognitive impairment where all aspects of behavior are affected $(2,3)$. Previous studies have suggested various pathways for the pathogenesis of $\mathrm{AD}$, including genetic variations (4), internal and external environmental factors (5), abnormal protein modification $(6,7)$, neural plasticity changes $(8,9)$ and oxidative stress $(10,11)$. However, the exact pathogenesis of AD remains unclear.

Mitochondria have been identified to serve a critical role in the pathogenesis of AD. Postmortem results have revealed abnormal mitochondrial ultrastructures and reduced activities of mitochondrial localized enzymes $(12,13)$, reduced mitochondrial numbers (14) and decreased mitochondrial oxygen consumption (15) in AD patients. Furthermore, extracellular amyloid $\beta$ (A $\beta)$ deposition is centrally associated with the pathogenesis of mitochondrial dysfunction in AD. Cytoplasmic blebbing, mitochondrial calcium dyshomeostasis, cytochrome $c$ release, chromatin condensation, nuclear damage and DNA fragmentation may be activated locally following exposure to $A \beta$ (16). In addition, increased intracellular $A \beta$ levels facilitate opening of the mitochondrial permeability transition pores (17). Notably, defective mitochondrial function has been implicated as an early event in the progression of AD (18). Therefore, it appears that mitochondria are a potential target for early-stage AD treatment.

Statins, also known as hydroxymethyl glutaryl coenzyme A reductase inhibitors, were first approved for use in 1987 (19). Simvastatin (SV) is a statin that is widely used in the prevention and treatment of atherosclerosis associated with cerebrovascular diseases. Notably, clinical data have demonstrated that $\mathrm{SV}$ is able to ameliorate the symptoms or delay the progression of cognitive impairment in AD patients with mild cognitive impairment (20). Previous studies by the 
present research team indicated that SV clearly improved the cognitive function and increased cerebral blood flow in amyloid precursor protein transgenic mice $(21,22)$. In addition, SV has been shown to enhance the human osteoblast proliferation associated with mitochondrial energy generation (23), and protect human osteosarcoma cells against oxidative stress-induced apoptosis through mitochondrial mediated signaling (24). These data suggest that the anti-AD effect of SV is potentially associated with the attenuation of mitochondrial dysfunction. Therefore, the aim of the present study was to evaluate the role of SV in mitochondrial dysfunction in $\mathrm{AD}$ using an in vitro approach.

\section{Materials and methods}

Culture of SH-SY5Y cells. The study was conducted using SH-SY5Y human neuroblastoma cells (a gift from Dr Zunji Ke, Institute for Nutritional Sciences, Chinese Academy of Sciences, Shanghai, China), who purchased the cells from American Type Culture Collection (Manassas, VA, USA). The two laboratories made every effort to keep the cell line pure and free from contamination. The cells were cultured in minimum essential medium and Ham's F-12 nutrient mix (MEM/F12, 1:1), supplemented with $10 \%$ fetal bovine serum (FBS) (both Gibco; Thermo Fisher Scientific, Inc., Waltham, MA, USA), 100 U/ml penicillin and $100 \mathrm{U} / \mathrm{ml}$ streptomycin at $37^{\circ} \mathrm{C}$ in a humidified atmosphere of $5 \% \mathrm{CO}_{2}$ (Thermo Fisher Scientific, Inc.). The cells were subcultured every 3 days.

Cell viability assay. The cells were plated at a density of $\sim 3 \times 10^{4}$ viable cells/well in 96-well plates. The cells were treated with $0,1,10,100$ and 1,000 $\mathrm{nM}$ concentrations of SV (Sigma-Aldrich; Merck KGaA, Darmstadt, Germany), or with $0,1,5$ and $10 \mu \mathrm{M}$ concentrations of human amyloid- $\beta 1-42$ peptide $\left[\mathrm{A} \beta_{1-42}\right.$; Chinapeptide Co., Ltd., Shanghai, China) for $24 \mathrm{~h}$. Combination treatments were also administered, where the cells were pretreated with SV for $24 \mathrm{~h}$ prior to treatment with $A \beta_{1-42}$ for $24 \mathrm{~h}$. The $A \beta_{1-42}$ was dissolved in distilled water, then diluted with phosphate-buffered saline (PBS) and incubated at $37^{\circ} \mathrm{C}$ for $72 \mathrm{~h}$ prior to use. A 3-(4,5-dimethylthiazol-2-yl)-2,5-diphenyltetrazolium bromide (MTT; Sigma-Aldrich; Merck KGaA) assay was performed to measure cell viability using a 96-well plate reader (SpectraMax 190; Molecular Devices, LLC, Sunnyvale, CA, USA). For the cell viability assay, dimethylsulfoxide was used to dissolve the purple formazan after MTT staining. The wavelength used to measure formazan was $570 \mathrm{~nm}$.

Hoechst 33342 staining. Cells were stained with $10 \mu \mathrm{g} / \mathrm{ml}$ Hoechst 33342 (Invitrogen; Thermo Fisher Scientific, Inc.) for $15 \mathrm{~min}$ at $37^{\circ} \mathrm{C}$. Nuclear morphological changes were analyzed using a fluorescence microscope (Nikon Corporation, Tokyo, Japan).

Apoptosis assay by flow cytometry. Cells were tested with an Alexa Fluor ${ }^{\circledR} 488$ Annexin V/Dead Cell Apoptosis kit with Alexa $^{\circledR}$ (Invitrogen; Thermo Fisher Scientific, Inc.) according to the manufacturer's protocol. Briefly, following treatment, the cells were harvested and stained with Annexin V and propidium iodide (PI) fluorescent dyes. The stained cells were then analyzed by flow cytometry (CFlow Plus 1.0.264.15; BD Biosciences, Franklin Lakes, NJ, USA).

Intracellular reactive oxygen species (ROS) determination. ROS levels were measured using the non-fluorescent probe dichlorofluorescin diacetate (DCFH-DA; Beyotime Institute of Biotechnology, Shanghai, China). The cells were incubated with DCFH-DA at $37^{\circ} \mathrm{C}$ for $30 \mathrm{~min}$, and the distribution of DCF fluorescence was detected using a fluorescence microplate reader (Spectra MaxGemini; Molecular Devices, LLC) at an excitation wavelength of $488 \mathrm{~nm}$ and emission wavelength of $535 \mathrm{~nm}$. The cells were observed using a fluorescence microscope.

Assessment of mitochondrial membrane potential (MMP). A fluorescent dye, 5,5',6,6'-tetrachloro-1,1',3,3'-tetraethylbenzimidazol-carbocyanine iodide (JC-1; Molecular Probes; Thermo Fisher Scientific, Inc.) was used to monitor the MMP. The cells were incubated with $5 \mu \mathrm{g} / \mathrm{ml} \mathrm{JC}-1$ for $30 \mathrm{~min}$ at $37^{\circ} \mathrm{C}$, then observed using a fluorescence microscope. Fluorescence was quantified using a fluorescence microplate reader (Spectra MaxGemini). Red fluorescence intensity was detected at an excitation wavelength of $488 \mathrm{~nm}$ and emission wavelength of $595 \mathrm{~nm}$ and green fluorescence intensity was detected at an excitation wavelength of $488 \mathrm{~nm}$ and emission wavelength of $525 \mathrm{~nm}$. When MMP was low, the JC-1 fluorescent dye existed as a monomer, which presented green fluorescence; while it existed as polymer, which presented red fluorescence when MMP was high.

Firefly luciferase adenosine triphosphate (ATP) assay. ATP was quantified using the luciferin-luciferase method. Cells were harvested following treatment and assayed for ATP using an ATP assay kit (Beyotime Institute of Biotechnology). In brief, cells were lysed by the addition of $100 \mu \mathrm{l}$ ATP-releasing reagent. The lysates were incubated with the luciferin substrate and luciferase enzyme in the dark for $10 \mathrm{~min}$ to stabilize the luminescent signal. A fluorescence microplate reader was used to measure the bioluminescence intensity.

Oxygen consumption measurement. A Clark oxygen electrode (Oxygraph 1.01; Hansatech Instruments, Ltd., King's Lynn, UK) was used to estimate the change of oxygen consumption of the cells. A small stir bar maintained the cells in suspension, and a Peltier heating block maintained the temperature at $37^{\circ} \mathrm{C}$. Data from the electrode were exported to a computerized chart recorder, which calculated the rate of oxygen consumption.

Assessment of mitochondrial mass. Cells were incubated with $1 \mu \mathrm{g} / \mathrm{ml}$ MitoTracker Red FM (Molecular Probes; Thermo Fisher Scientific, Inc.) at $37^{\circ} \mathrm{C}$ for $30 \mathrm{~min}$, and the fluorescence intensity was detected using a fluorescence microplate reader at an excitation wavelength of $581 \mathrm{~nm}$ and emission wavelength of $644 \mathrm{~nm}$. Cells were observed using a fluorescence microscope.

Western blot analysis. Following treatment, $1 \times 10^{6}$ cells were collected and equal amounts of protein samples were subjected to western blot analysis, as previously described (25). The release of cytochrome $c$ from the mitochondria to the cytosol was measured using western blotting as reported by Piqué et al (26). Lysates were centrifuged at $12,000 \mathrm{x} \mathrm{g}$ at $4^{\circ} \mathrm{C}$ for $15 \mathrm{~min}$ to obtain supernatants 
A

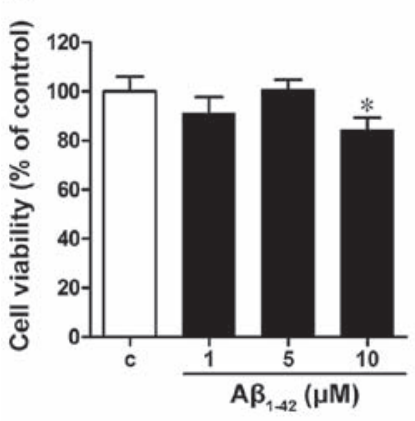

B

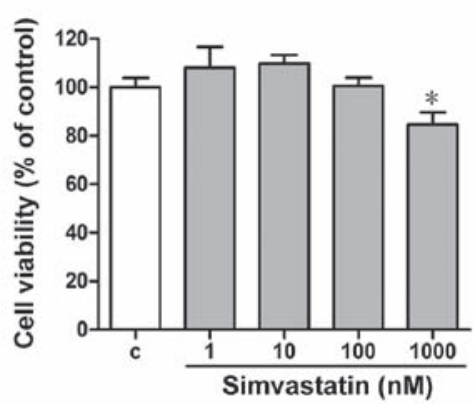

C

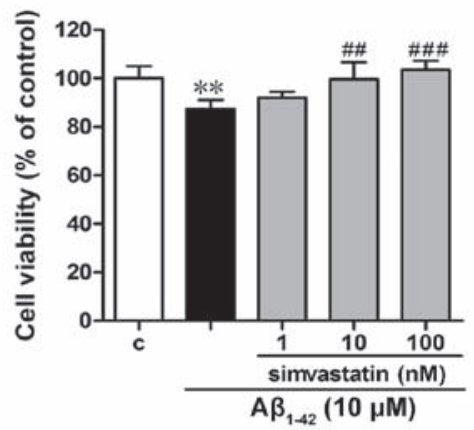

D
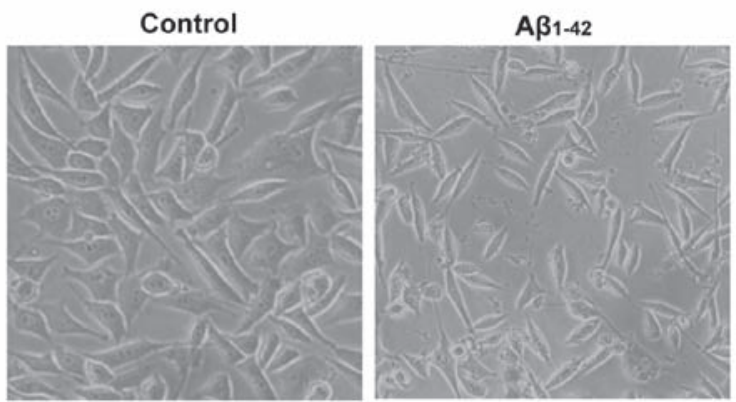

$A \beta 1-42+S V(1 \mathrm{nM})$

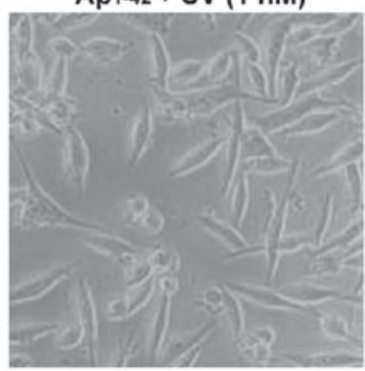

$A \beta 1-42+S V(10 \mathrm{nM})$

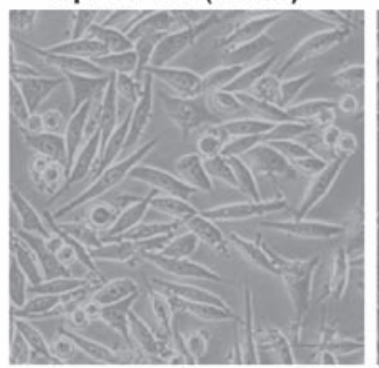

$A \beta 1-42+S V(100 n M)$

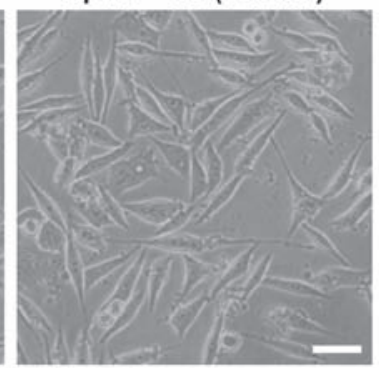

Figure 1. Simvastatin protects against A $\beta_{1-42}$-induced cytotoxicity in SH-SY5Y cells. Cell viability was determined by MTT assay. (A) A $\beta_{1-42}$ was cytotoxic to SH-SY5Y cells. (B) Effect of simvastatin on cell viability. (C) Simvastatin protected against A $\beta_{1-42}$-induced cytotoxicity in SH-SY5Y cells. (D) Microscopy showing the effect of simvastatin on $\mathrm{A} \beta_{1-42}$-induced cytotoxicity in SH-SY5Y cells. Scale bar, $50 \mu \mathrm{m}$. Values are presented as the mean \pm standard deviation $(\mathrm{n}=5)$. ${ }^{*} \mathrm{P}<0.05$ and ${ }^{* *} \mathrm{P}<0.01$ vs. control; ${ }^{\# \#} \mathrm{P}<0.01$ and ${ }^{\# \# \#} \mathrm{P}<0.001$ vs. only $\mathrm{A} \beta_{1-42}$ treatment. $\mathrm{A} \beta_{1-42}$, amyloid $\mathrm{A} \beta_{1-42} ; \mathrm{SV}$, simvastatin; $\mathrm{c}, \mathrm{control}$.

(cytosolic extracts free of mitochondria) and the pellets (the mitochondria-containing fraction). The supernatants and pellets were subjected to western blotting as described in the aforementioned references. The following primary antibodies were used: Mouse anti-B-cell lymphoma 2 (Bcl-2) antibody (1:1,000; \#15071; Cell Signaling Technology, Inc., Danvers, MA, USA), rabbit anti-Bcl-2-associated X protein (Bax) antibody (1:1,000; ab32503; Abcam, Cambridge, MA, USA), mouse anti-peroxisome proliferator-activated receptor $\gamma$ coactivator-1 $\alpha$ (PGC-1 $\alpha$ ) antibody (1:100; sc-518025; Santa Cruz Biotechnology, Inc., Dallas, TX, USA), mouse anti-cytochrome $c$ antibody (1:100; \#3026; BioVision, Inc., Miliptas, CA, USA), rabbit anti-voltage-dependent anion channel (VDAC) antibody (1:100; sc-98708; Santa Cruz Biotechnology, Inc.), rabbit anti-caspase-3 antibody $(1: 1,000$; ab90437; Abcam) and mouse anti- $\beta$-actin antibody $(1: 2,000$; ab11003; Abcam). Visualization of the immunolabeled bands was carried out using a chemiluminescence imaging system. The chemiluminescence reagent was Immobilon Western chemiluminescent HRP substrate (WBKLS0500; Millipore, Billerica, MA, USa). Image J (version k 1.45) software was used for the quantification of the western blots.
Statistical analysis. Data are expressed as the mean \pm standard deviation and were compared by one-way analysis of variance followed by Newman-Keuls post-hoc multiple-comparison tests. The statistical analysis was conducted using GraphPad Prism 5 software (GraphPad Software, Inc., La Jolla, CA, USA). P<0.05 was considered to indicate a statistically significant difference.

\section{Results}

$S V$ protects against $A \beta_{1-42}$-induced cytotoxicity in $S H-S Y 5 Y$ cells. The effects of $\mathrm{A} \beta_{1-42}$ and SV on SH-SY5Y cells were detected. The viability of the cells treated with $10 \mu \mathrm{M}$ $\mathrm{A} \beta_{1-42}$ was significantly decreased compared with that of the untreated control group (Fig. 1A). Low concentrations of SV $(\leq 100 \mathrm{nM})$ exhibited no effect on the viability of SH-SY5Y cells, whilst 1,000 $\mathrm{nM} \mathrm{SV} \mathrm{significantly} \mathrm{reduced} \mathrm{the} \mathrm{viability}$ of the cells (Fig. 1B). Exposure to $10 \mu \mathrm{M} \mathrm{A} \beta_{1-42}$ for $24 \mathrm{~h}$ significantly decreased cell viability compared with that of the control cells, and pretreatment with 10 or $100 \mathrm{nM} \mathrm{SV}$ for $24 \mathrm{~h}$ significantly attenuated the $\mathrm{A} \beta_{1-42}$-induced reduction in viability (Fig. 1C). Morphological observations revealed that the cell number was clearly reduced when cells were treated 


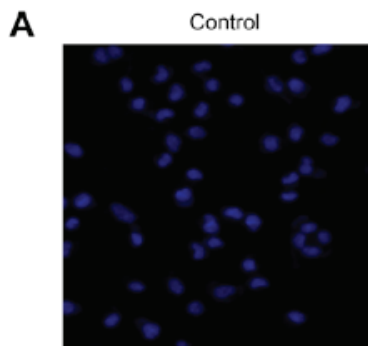

$A \beta_{1.42}+\mathrm{SV}(10 \mathrm{nM})$

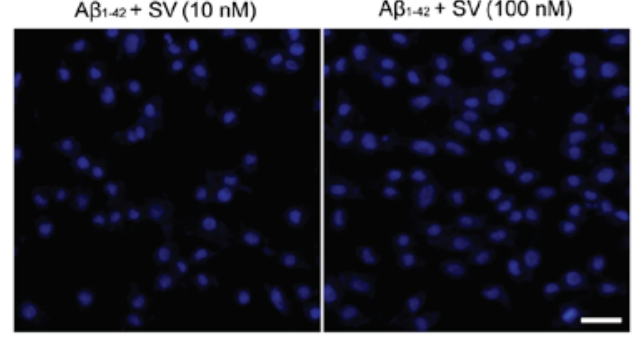

B
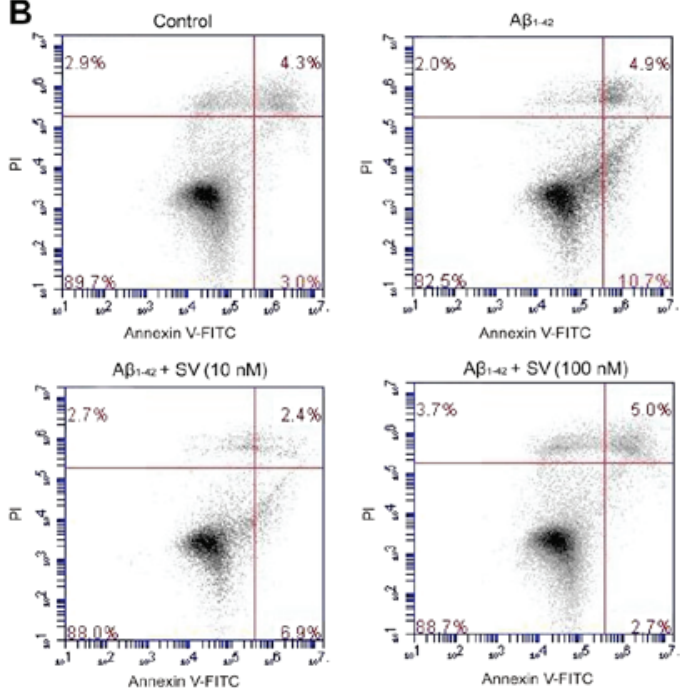

E

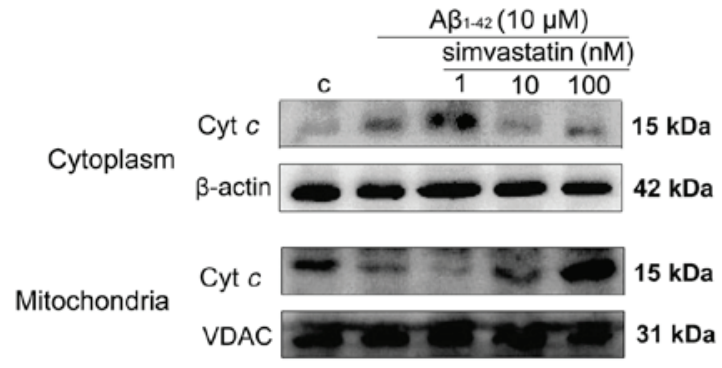

$A \beta_{1.42}+S V(1 \mathrm{nM})$
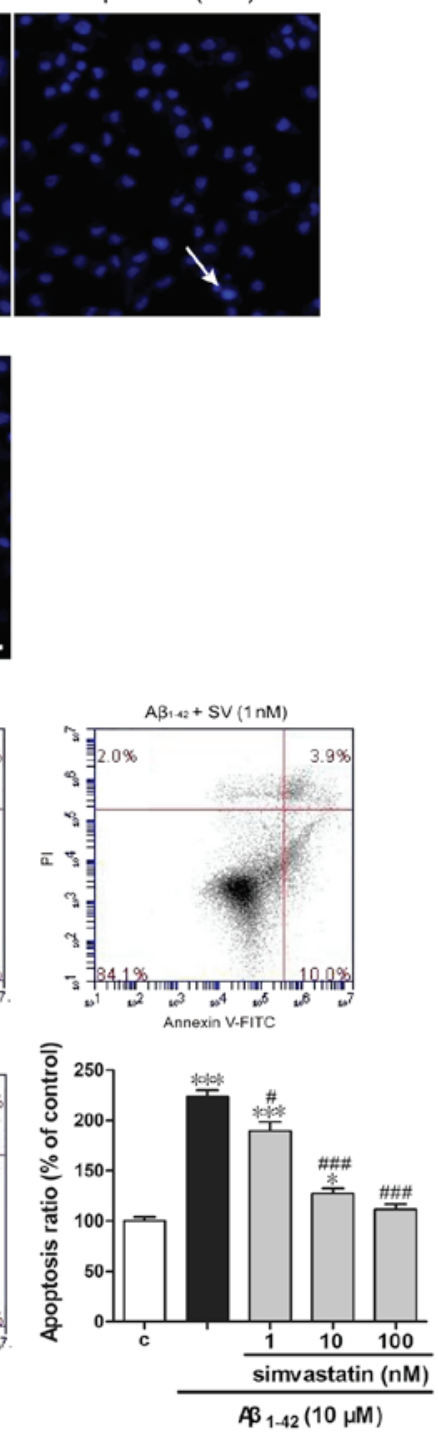

C
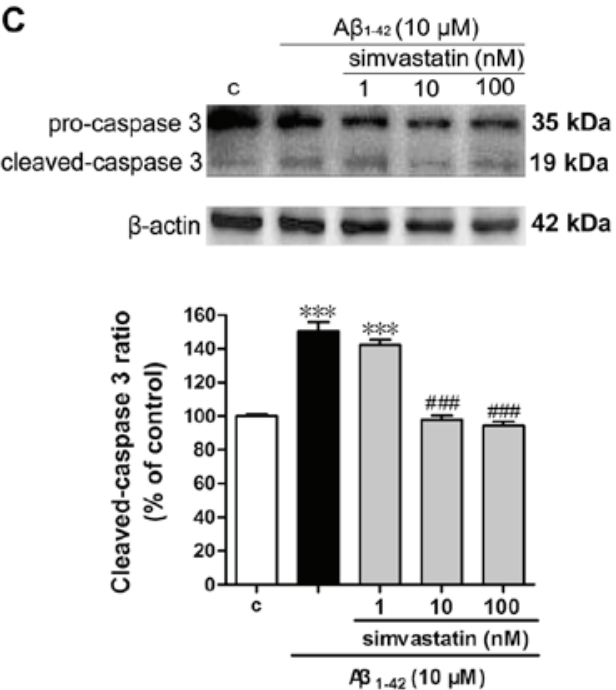

D
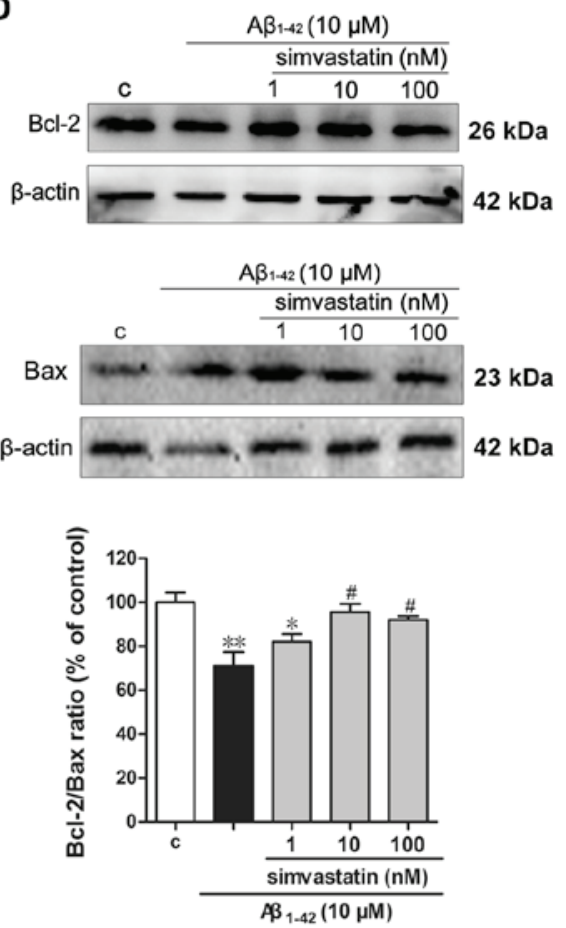
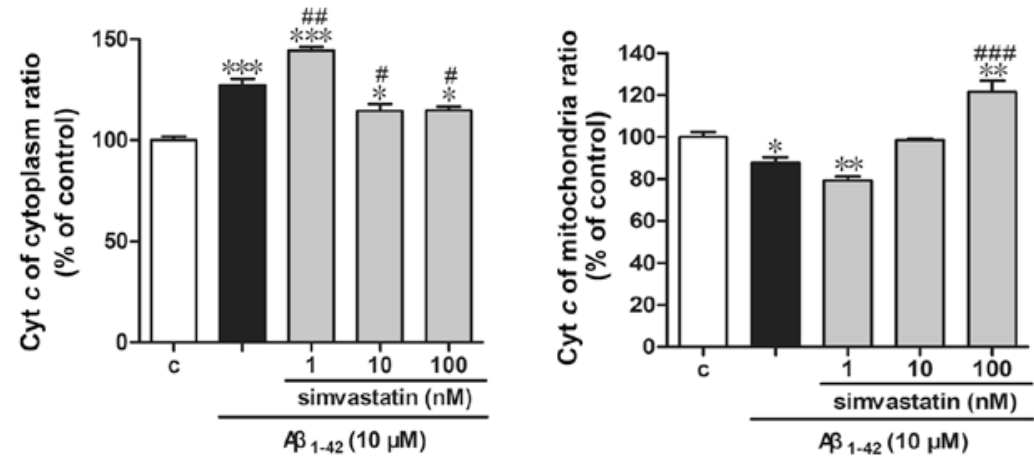

Figure 2. Simvastatin decreases A $\beta_{1-42}$-induced apoptosis in SH-SY5Y cells. (A) Cells stained with Hoechst 33342 observed using fluorescence microscopy exhibit apoptotic changes (arrows). Scale bar, $100 \mu \mathrm{m}$. (B) Analysis of cells stained with Annexin V/PI by flow cytometry. Western blotting shows that simvastatin (C) decreased cleaved-caspase-3 levels, (D) increased the Bcl-2/Bax protein ratio and (E) inhibited the release of cyt $c$ from mitochondria to cytoplasm. Data are presented as mean \pm standard deviation $(\mathrm{n}=3) .{ }^{*} \mathrm{P}<0.05,{ }^{* *} \mathrm{P}<0.01$ and ${ }^{* * * *} \mathrm{P}<0.001$ vs. control; ${ }^{\#} \mathrm{P}<0.05,{ }^{\# \#} \mathrm{P}<0.01$ and ${ }^{\# \# \#} \mathrm{P}<0.001$ vs. only $\mathrm{A} \beta_{1-42}$ treatment. $\mathrm{A} \beta_{1-42}$, amyloid $\mathrm{A} \beta_{1-42} ; \mathrm{SV}$, simvastatin; c, control; Bcl-2, B-cell lymphoma 2; Bax, anti-Bcl-2-associated X protein; PI, propidium iodide; Cyt $c$, cytochrome $c$. 
A
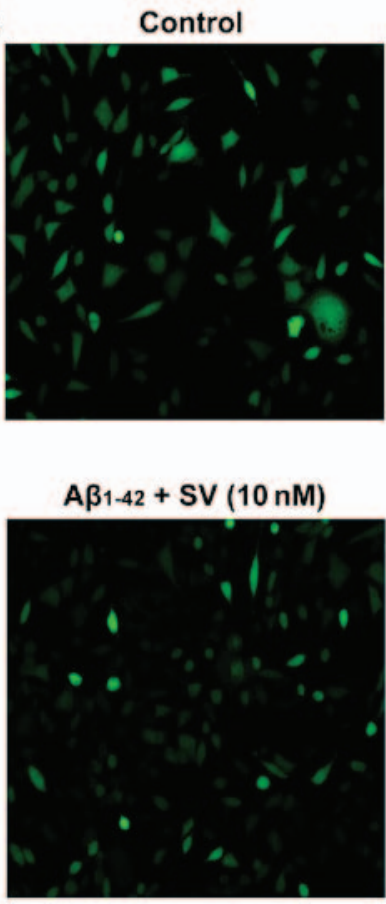
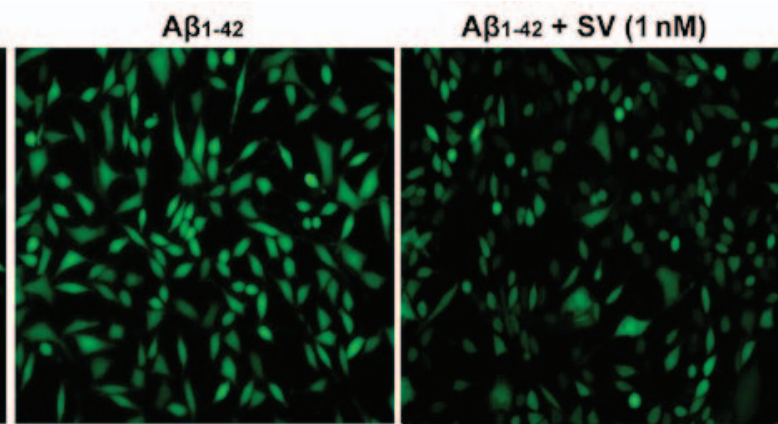

B

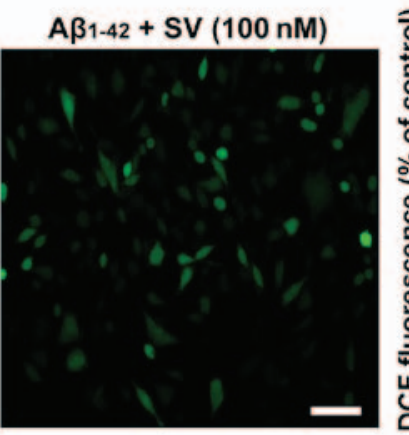

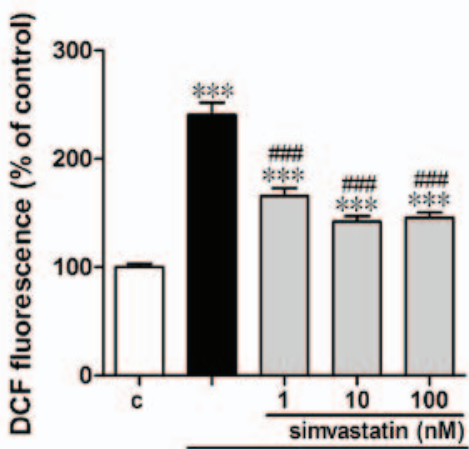

$A \beta_{1-42}(10 \mu \mathrm{M})$

Figure 3. Simvastatin protects against $\mathrm{A} \beta_{1-42}$-induced ROS elevation. (A) Simvastatin decreased the generation of ROS induced by $10 \mu \mathrm{M} A \beta_{1-42}$ in SH-SY5Y cells. DCF fluorescence staining; scale bar, $100 \mu \mathrm{m}$. (B) Quantitative results assayed using a fluorescence microplate reader. Data are presented as the mean \pm standard deviation $(\mathrm{n}=5) .{ }^{* * *} \mathrm{P}<0.001$ vs. control; ${ }^{\# \# \#} \mathrm{P}<0.001$ vs. only $\mathrm{A} \beta_{1-42}$ treatment. A $\beta_{1-42}$, amyloid $\mathrm{A} \beta_{1-42} ; \mathrm{SV}$, simvastatin; c, control; ROS, intracellular reactive oxygen species; DCF, dichlorofluorescein.

with $10 \mu \mathrm{M} \mathrm{A} \beta_{1-42}$ (Fig. 1D). The cell numbers of the groups that were pretreated with SV were markedly increased when compared with those in the $\mathrm{A} \beta_{1-42}$-treated group (Fig. 1D).

SV decreases the A $\beta_{1-42}$-induced apoptosis of SH-SY5Y cells. Hoechst 33342 staining demonstrated that the cells treated with $10 \mu \mathrm{M} \mathrm{A} \beta_{1-42}$ underwent chromatin condensation and nuclear fragmentation (indicated by arrows; Fig. 2A). This suggested that the cell death induced by $A \beta_{1-42}$ involved apoptosis. The cell apoptotic rate was detected by flow cytometry with Annexin V/PI-staining of the cells. The apoptotic rate in the $\mathrm{A} \beta_{1-42}$ treatment group was $15.6 \%$, which was $\sim 2$-fold greater than that of the control group. The apoptotic rates in the SV treatment groups (those treated with SV and $\mathrm{A} \beta_{1-42}$,) were significantly decreased compared with those in the group treated with $A \beta_{1-42}$ alone. Notably, the apoptosis level of the $100 \mathrm{nM} \mathrm{SV}$ treatment group was $7.7 \%$, and was almost restored to the level of the control group (Fig. 2B). To further examine the pathway of apoptosis, caspase-3 content in the cytosol, which is the final executor of the apoptotic process (27), was examined using western blot analysis. When compared with the control group, cleaved-caspase-3 protein levels were significantly increased in the $10 \mu \mathrm{M} \mathrm{A} \beta_{1-42}$ group, suggesting that $\mathrm{A} \beta_{1-42}$ induced apoptosis through a caspase-dependent pathway (Fig. 2C). Following pretreatment with 10 and $100 \mathrm{nM}$ $\mathrm{SV}$, the protein levels of cleaved-caspase-3 was significantly decreased compared with those in the group treated with $A \beta_{1-42}$ alone. In addition, the $\mathrm{Bcl}-2 / \mathrm{Bax}$ protein ratio was significantly reduced following treatment with $A \beta_{1-42}$ compared with that in the control group. However, pretreatment with 10 and $100 \mathrm{nM}$ $\mathrm{SV}$ significantly increased the Bcl-2/Bax protein ratio, which suggests an anti-apoptotic effect (Fig. 2D). Furthermore, $A \beta_{1-42}$ induced the release of cytochrome $c$ from the mitochondria to the cytoplasm, and SV inhibited this release of cytochrome $c$ (Fig. 2E).

$S V$ protects against $A \beta_{1-42}$-induced intracellular ROS elevation. To determine whether $\mathrm{A} \beta_{1-42}$ increased the intracellular ROS level, cells were labeled with DCFH-DA and then examined under a fluorescence microscope and using a fluorescence microplate reader (Fig. 3). Treatment with $10 \mu \mathrm{M} \mathrm{A} \beta_{1-42}$ for $24 \mathrm{~h}$ led to a significant increase in fluorescence intensity compared with that of the control group (Fig. 3B). In comparison with the $10 \mu \mathrm{M} \mathrm{A} \beta_{1-42}$ treatment group, SV significantly attenuated ROS accumulation at all three concentrations. Representative fluorescence photomicrographs (Fig. 3A) are consistent with the quantitative results.

$S V$ protects against $A \beta_{1-42}$ induced mitochondrial dysfunction by increasing MMP, intracellular ATP level and the cell respiration rate. To determine whether $\mathrm{A} \beta_{1-42}$ affects mitochondrial function, the changes of MMP were investigated. Treatment of the cells with $10 \mu \mathrm{M} \mathrm{A} \beta_{1-42}$ resulted in increased green fluorescence intensity and reduced red fluorescence intensity of JC-1 compared with that in the control group, which indicates that the MMP was decreased (Fig. 4A). Pretreatment with SV increased the red fluorescence intensity and reduced the green fluorescence intensity, indicating that SV protected against the depolarization of the mitochondrial membrane induced by $\mathrm{A} \beta_{1-42}$. The quantified red/green fluorescence ratios (Fig. 4B) were consistent with the fluorescence photomicrographs. MMP is the driving force of ATP synthesis, and the loss of 
A
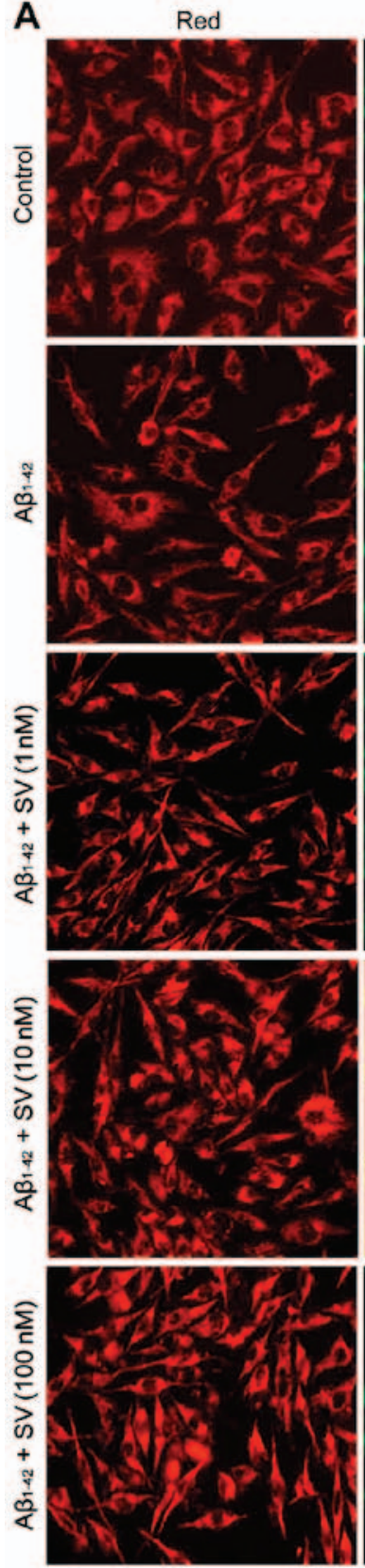

Green
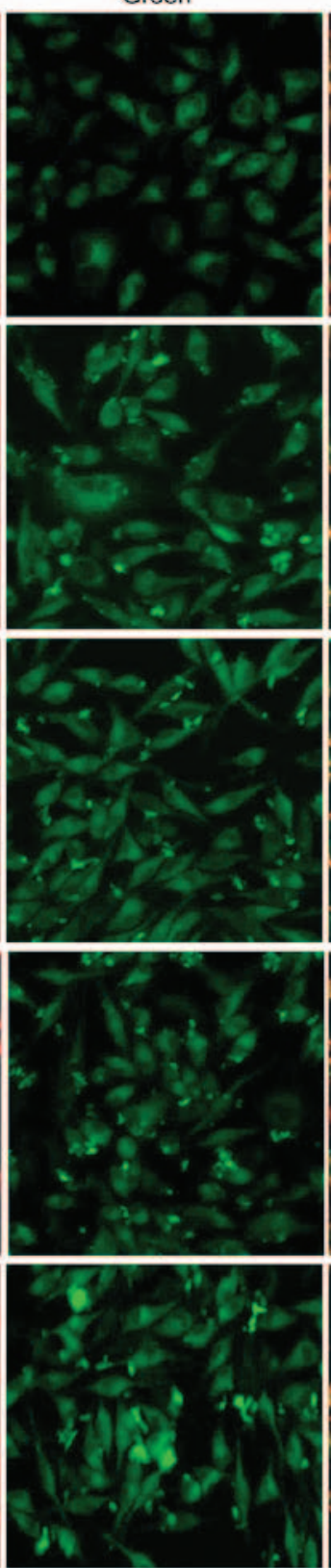

Merge
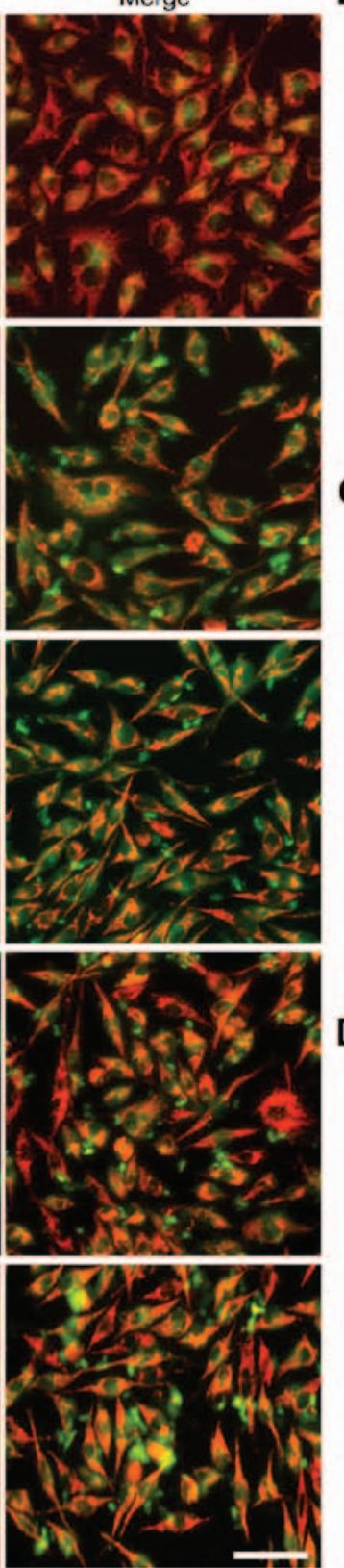

B

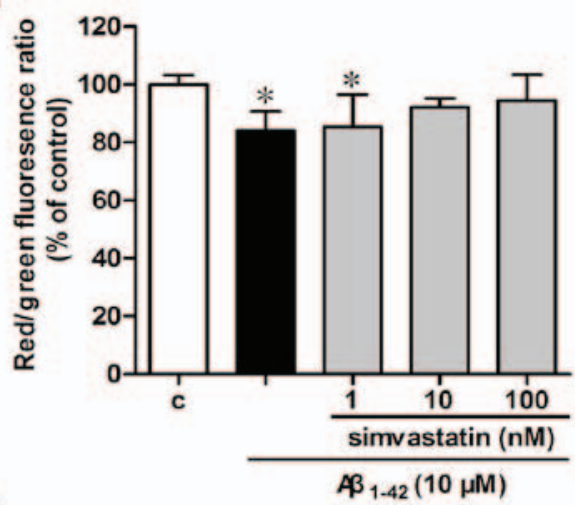

C
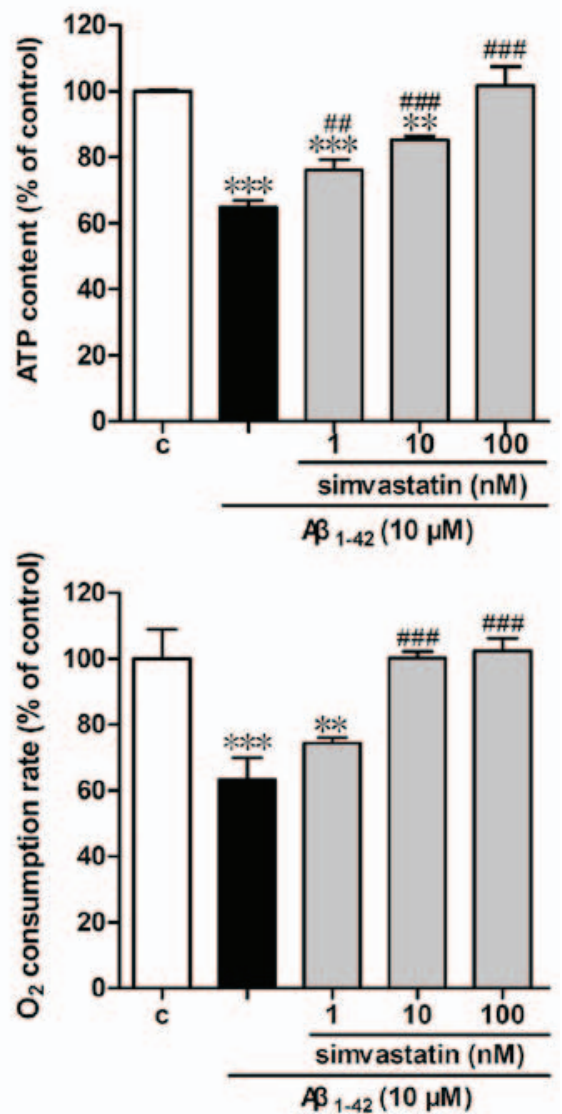

Figure 4. Simvastatin protects against $A \beta_{1-42}$-induced mitochondrial dysfunction. Changes of mitochondria stained with JC-1 were (A) visualized using fluorescence microscopy and (B) detected using a fluorescence microplate reader. Scale bar, $50 \mu$ m. (C) ATP levels were measured with the luciferin-luciferase assay. (D) Cell respiration rates were determined using a Clark oxygen electrode. Data are presented as mean \pm standard deviation; (B) $n=5$ and $(C$ and $D) n=3$. ${ }^{*} \mathrm{P}<0.05,{ }^{* *} \mathrm{P}<0.01$ and ${ }^{* * *} \mathrm{P}<0.001$ vs. control; ${ }^{\# \#} \mathrm{P}<0.01$ and ${ }^{\# \# \#} \mathrm{P}<0.001$ vs. only $\mathrm{A} \beta_{1-42}$ treatment. A $\beta_{1-42}$, amyloid $\mathrm{A} \beta_{1-42} ; \mathrm{SV}$, simvastatin; c, control; JC-1, 5,5',6,6'-tetrachloro-1,1',3,3'-tetraethylbenzimidazol-carbocyanine iodide; ATP, adenosine triphosphate.

MMP is expected to result reduce the ATP level in cells; thus, the cellular ATP level is an important determinant of cell death (28). As demonstrated in Fig. $4 \mathrm{C}, 10 \mu \mathrm{M} \mathrm{A} \beta_{1-42}$ induced a significant reduction in cellular ATP content compared with that in the control group. Intracellular ATP levels increased following pretreatment with all three concentrations of SV. As the intracellular ATP level is associated with the cell respiration rate, a Clark oxygen electrode was used to determine the cell respiration rate. As demonstrated in Fig. 4D, compared with the control group, treatment with $10 \mu \mathrm{M} \mathrm{A} \beta_{1-42}$ led to a significant reduction in cell respiration rate, which was significantly attenuated by pretreatment with 10 or $100 \mathrm{nM} \mathrm{SV}$.
$S V$ protects against $A \beta_{1-42}$ induced reductions in mitochondrial number. MitoTracker Red staining was used to examine the numbers of mitochondria. As demonstrated in Fig. 5A, the red fluorescence of the $A \beta_{1-42}$ treatment group was weak compared with that of the control group, whilst pretreatment with SV increased the fluorescence intensity compared with that of the $A \beta_{1-42}$ treatment group. The quantitative results (Fig. 5B) were consistent with the fluorescence photomicrographs. As PGC-1 $\alpha$ has been demonstrated to be associated with mitochondrial biogenesis (29), the expression of PGC-1 $\alpha$ was detected by western blotting. As demonstrated in Fig. 5C, 10 and $100 \mathrm{nM}$ SV significantly increased PGC-1 $\alpha$ protein levels. 


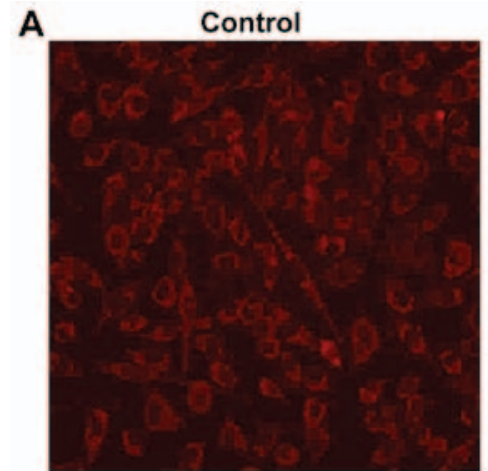

$A \beta 1-42+S V(10 n M)$

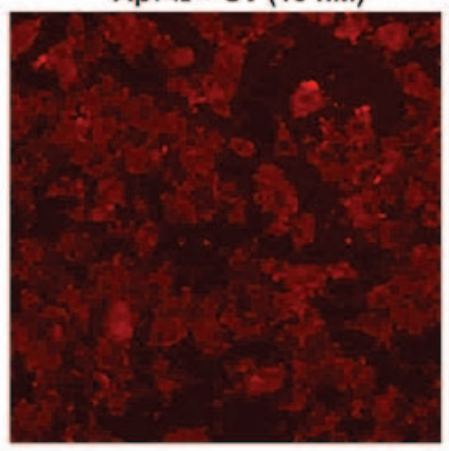

C

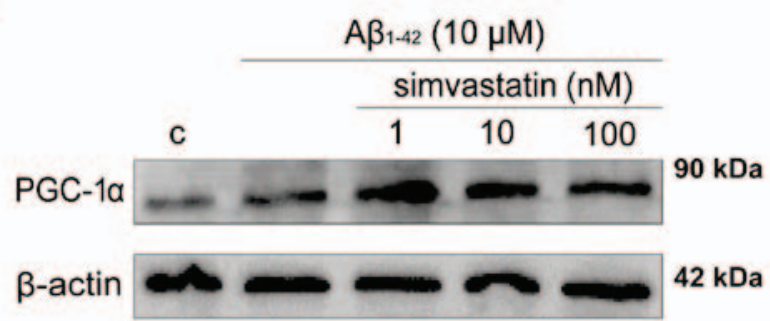

$A \beta 1.42$

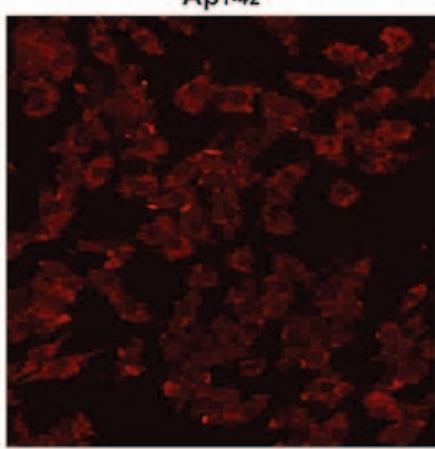

$A \beta 1-42+S V(100 \mathrm{nM})$

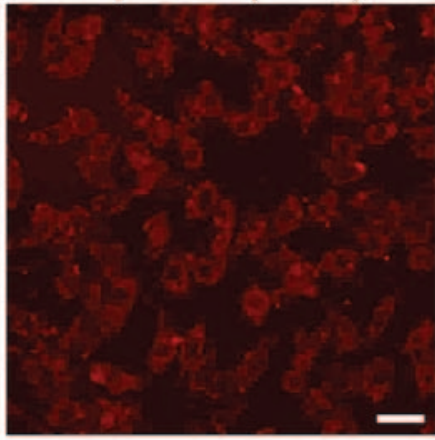

B
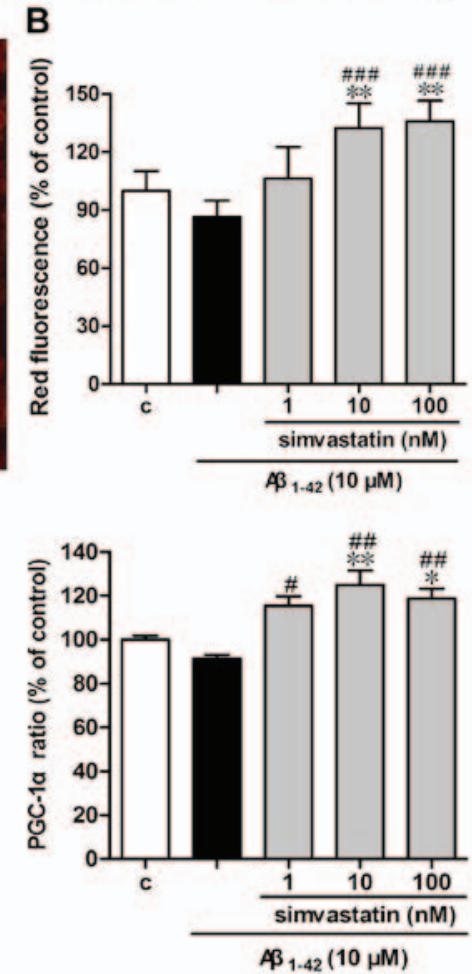

Figure 5. Simvastatin protects against $\mathrm{A} \beta_{1-42}$-induced reductions in mitochondrial number. Changes of mitochondria stained with MitoTracker Red were (A) visualized using fluorescence microscopy and (B) detected using a fluorescence microplate reader. Scale bar, $50 \mu \mathrm{m}$. (C) Western blotting demonstrated that simvastatin increased the expression of $\mathrm{PGC}-1 \alpha$. Data are presented as mean \pm standard deviation; (B) $\mathrm{n}=5$ and $(\mathrm{C}) \mathrm{n}=3$. ${ }^{*} \mathrm{P}<0.05$ and ${ }^{* *} \mathrm{P}<0.01 \mathrm{vs}$. control;

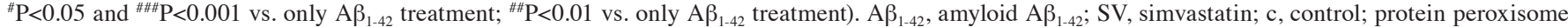
proliferator-activated receptor $\gamma$ coactivator- $1 \alpha$.

\section{Discussion}

In the present study, the role of $\mathrm{SV}$ in $\mathrm{A} \beta_{1-42}$-induced injury was investigated in vitro, and the results provide novel evidence that modulation of mitochondrial function is an important mechanism by which SV attenuates $\mathrm{A} \beta_{1-42}$-induced SH-SY5Y cell insult.

$\mathrm{A} \beta$ is considered to serve a central role in the pathogenesis of AD. Mei et al (30) revealed that the viability of SH-SY5Y cells significantly decreased in a concentration-dependent manner following treatment with $A \beta_{1-42}$. The findings of the present study are consistent with these results. The $10 \mu \mathrm{M}$ concentration of $\mathrm{A} \beta_{1-42}$ was chosen for testing in subsequent experiments.

The mitochondrial pathway is a major apoptosis signaling pathway. The mitochondrial pathway of apoptosis is regulated by the Bcl-2 family proteins consisting of two subgroups according to structural homology: Anti-apoptotic proteins such as Bcl-2 and pro-apoptotic proteins such as Bax (31).
Furthermore, anti-apoptotic Bcl-2 has been indicated to inhibit ROS production (32), while pro-apoptotic Bax induces ROS production. In addition, increased intracellular A $\beta$ levels facilitate the opening of mitochondrial permeability transition pores resulting in the release of cytochrome $c$ into the cytoplasm and activation of caspase-3, which induces cell apoptosis (33). In the present study, Annexin V/PI staining data indicated that SV significantly inhibited the $A \beta_{1-42}$ induced SH-SY5Y cell apoptosis. To further study the molecular mechanisms underlying the anti-apoptotic activity of SV, the expression levels of Bcl-2, Bax, cytochrome $c$ and cleaved-caspase-3 were evaluated using western blot analysis. The results demonstrated that SV inhibited the release of cytochrome $c$ from the mitochondria to the cytoplasm, downregulated the protein levels of Bax and cleaved-caspase-3, and upregulated Bcl-2 protein levels in $\mathrm{A} \beta_{1-42}$-treated $\mathrm{SH}-\mathrm{SY} 5 \mathrm{Y}$ cells, indicating that $\mathrm{SV}$ inhibited $\mathrm{A} \beta_{1-42}$-induced apoptosis partially through regulation of the mitochondrial apoptosis pathway. 
Oxidative stress is considered to have an association with AD (34). Notably, oxidative stress may be an early event in disease progression, as a previous study indicated that $A \beta$ binds to $A \beta$-binding alcohol dehydrogenase, resulting in an increase in ROS generation and reduction in ATP production (35). In the present study, ROS generation in the $\mathrm{A} \beta$ treatment group was increased significantly compared with that in the control cells. However, in the SV treatment groups, the $\mathrm{A} \beta_{1-42}$-induced ROS generation was decreased significantly compared with that in the $A \beta$ treatment group, which indicates that SV inhibited the intracellular ROS generation induced by $A \beta$.

Researchers have focused on a potential link between AD and abnormal pathophysiological events in mitochondria (36-38). The MMP maintains its regular oxidative phosphorylation state for the continuous production of ATP (39) and its dissipation is regarded as the early landmark of cell apoptosis (40). It has been reported that $\mathrm{A} \beta$ strongly influences mitochondrial respiratory function, ROS production and MMP $(41,42)$. In the present study, $A \beta_{1-42}$ was used to simulate mitochondrial dysfunction, in order to explore the neuroprotective effects of SV. To the best of our knowledge, the present study is the first to verify that SV pretreatment is able to prevent reductions in MMP and maintains the MMP at levels comparable with those of normal control cells. The results of the present study also indicate that $S V$ reversed $A \beta_{1-42}$-induced mitochondrial dysfunction by increasing intracellular ATP production, oxygen consumption and mitochondrial number. These results suggest that SV reversed the $A \beta_{1-42}$-induced neurotoxicity partially through the regulation of mitochondrial function.

In conclusion, the present study demonstrated for the first time that $\mathrm{SV}$ exerts a neuroprotective effect on $\mathrm{A} \beta_{1-42}$-induced neurotoxicity in SH-SY5Y cells, partially through regulation of the mitochondrial apoptosis pathway and mitochondrial function. These results suggest that the neuroprotective effects observed for SV in patients with $\mathrm{AD}$ are potentially associated with the ability of SV to protect the mitochondria against A $\beta$-induced neurotoxicity. However, the mechanism by which $\mathrm{SV}$ improves cognitive function requires further investigation in studies using animals.

\section{Acknowledgements}

Not applicable.

\section{Funding}

The present study was supported by the National Natural Science Foundation of China and Quebec Medical Research Foundation (grant no. 81361120247) and the National Natural Science Foundation of China (grant no. 81373400).

\section{Availability of data and materials}

The datasets used and/or analyzed during the current study are available from the corresponding author on reasonable request.

\section{Authors' contributions}

JG, XL and YL designed the study. YL, JS and JW performed majority of experiments and analyzed data. YL, QL and JG wrote and generated final draft of the manuscript. All authors read and approved the final manuscript.

\section{Ethics approval and consent to participate}

Not applicable.

\section{Consent for publication}

Not applicable.

\section{Competing interests}

The authors declare that they have no competing interests.

\section{References}

1. Prince M, Comas-Herrera A, Knapp M, Guerchet $\mathrm{M}$ and Karagiannidou M: World Alzheimer Report 2016 - Improving healthcare for people living with dementia: Coverage, quality and costs now and in the future. Alzheimer's Disease International, London.

2. Salmon DP: Neuropsychological features of mild cognitive impairment and preclinical Alzheimer's disease. Curr Top Behav Neurosci 10: 187-212, 2012

3. Förstl H and Kurz A: Clinical features of Alzheimer's disease. Eur Arch Psychiatry Clin Neurosci 249: 288-290, 1999.

4. Cong L and Jia J: Promoter polymorphisms which regulate ADAM9 transcription are protective against sporadic Alzheimer's disease. Neurobiol Aging 32: 54-62, 2011.

5. Tong Z, Zhang J, Luo W, Wang W, Li F, Li H, Luo H, Lu J, Zhou J, Wan Y, et al: Urine formaldehyde level is inversely correlated to mini mental state examination scores in senile dementia. Neurobiol Aging 32: 31-41, 2011.

6. Tong Z, Han C, Luo W, Wang X, Li H, Luo H, Zhou J, Qi J and He R: Accumulated hippocampal formaldehyde induces agedependent memory decline. Age (Dordr) 35: 583-596, 2013.

7. He R, Lu J and Miao J: Formaldehyde stress. Sci China Life Sci 53: 1399-1404, 2010.

8. Zhang X and Poo MM: Progress in neural plasticity. Sci China Life Sci 53: 322-329, 2010.

9. Luo Z: Synapse formation and remodeling. Sci China Life Sci 53: 315-321, 2010.

10. Zhang M, Zhao Z, He L and Wan C: A meta-analysis of oxidative stress markers in schizophrenia. Sci China Life Sci 53: 112-124, 2010.

11. Sun P,Zhang Q,Han J, Tian Y and Zhang J: TLR4 signaling induced TLR2 expression in the process of mimic cerebral ischemia/reperfusion in vitro. Sci China Life Sci 53: 223-228, 2010.

12. Perry EK, Perry RH, Tomlinson BE, Blessed G and Gibson PH: Coenzyme A-acetylating enzymes in Alzheimer's disease: Possible cholinergic 'compartment' of pyruvate dehydrogenase. Neurosci Lett 18: 105-110, 1980.

13. Gibson GE, Sheu KF, Blass JP, Baker A, Carlson KC, Harding B and Perrino P: Reduced activities of thiamine-dependent enzymes in the brains and peripheral tissues of patients with Alzheimer's disease. Arch Neurol 45: 836-840, 1988.

14. Hirai K, Aliev G, Nunomura A, Fujioka H, Russell RL, Atwood CS, Johnson AB, Kress Y, Vinters HV, Tabaton M, et al: Mitochondrial abnormalities in Alzheimer's disease. J Neurosci 21: 3017-3023, 2001.

15. Sims NR, Finegan JM, Blass JP, Bowen DM and Neary D: Mitochondrial function in brain tissue in primary degenerative dementia. Brain Res 436: 30-38, 1987.

16. Eckert A, Keil U, Marques CA, Bonert A, Frey C, Schüssel K and Müller WE: Mitochondrial dysfunction, apoptotic cell death, and Alzheimer's disease. Biochem Pharmacol 66: 1627-1634, 2003.

17. Parks JK, Smith TS, Trimmer PA, Bennett JP Jr and Parker WD Jr: Neurotoxic Abeta peptides increase oxidative stress in vivo through NMDA-receptor and nitric-oxide-synthase mechanisms, and inhibit complex IV activity and induce a mitochondrial permeability transition in vitro. J Neurochem 76: 1050-1056, 2001 
18. Hauptmann S, Scherping I, Dröse S, Brandt U, Schulz KL, Jendrach M, Leuner K, Eckert A and Müller WE: Mitochondrial dysfunction: An early event in Alzheimer pathology accumulates with age in AD transgenic mice. Neurobiol Aging 30: 1574-1586, 2009.

19. Cucchiara B and Kasner SE: Use of statins in CNS disorders. J Neurol Sci 187: 81-89, 2001.

20. Simons M, Schwärzler F, Lütjohann D, von Bergmann K, Beyreuther K, Dichgans J, Wormstall H, Hartmann T and Schulz JB: Treatment with simvastatin in normocholesterolemic patients with Alzheimer's disease: A 26-week randomized, placebo-controlled, double-blind trial. Ann Neurol 52: 346-350, 2002.

21. Tong XK, Lecrux C, Rosa-Neto P and Hamel E: Age-dependent rescue by simvastatin of Alzheimer's disease cerebrovascular and memory deficits. J Neurosci 32: 4705-4715, 2012.

22. Tong XK, Nicolakakis N, Fernandes P, Ongali B, Brouillette J, Quirion R and Hamel E: Simvastatin improves cerebrovascular function and counters soluble amyloid-beta, inflammation and oxidative stress in aged APP mice. Neurobiol Dis 35: 406-414, 2009.

23. Chuang SC, Liao HJ, Li CJ, Wang GJ, Chang JK and Ho ML: Simvastatin enhances human osteoblast proliferation involved in mitochondrial energy generation. Eur J Pharmacol 714: 74-82, 2013.

24. Zhao XH, Xu ZR, Zhang Q and Yang YM: Simvastatin protects human osteosarcoma cells from oxidative stress-induced apoptosis through mitochondrial-mediated signaling. Mol Med Rep 5: 483-488, 2012

25. Xu MF, Xiong YY, Liu JK, Qian JJ, Zhu L and Gao J: Asiatic acid, a pentacyclic triterpene in Centella asiatica, attenuates glutamate-induced cognitive deficits in mice and apoptosis in SH-SY5Y cells. Acta Pharmacol Sin 33: 578-587, 2012.

26. Piqué M, Barragán M, Dalmau M, Bellosillo B, Pons G and Gil J: Aspirin induces apoptosis through mitochondrial cytochrome $c$ release. FEBS Lett 480: 193-196, 2000.

27. Danial NN and Korsmeyer SJ: Cell death: Critical control points. Cell 116: 205-219, 2004.

28. Zamzami N, Marchetti P, Castedo M, Decaudin D, Macho A, Hirsch T, Susin SA, Petit PX, Mignotte B and Kroemer G: Sequential reduction of mitochondrial transmembrane potential and generation of reactive oxygen species in early programmed cell death. J Exp Med 182: 367-377, 1995.

29. St-Pierre J, Drori S, Uldry M, Silvaggi JM, Rhee J, Jäger S, Handschin C, Zheng K, Lin J, Yang W, et al: Suppression of reactive oxygen species and neurodegeneration by the PGC-1 transcriptional coactivators. Cell 127: 397-408, 2006.
30. Mei Z, Yan P, Situ B, Mou Y and Liu P: Cryptotanshinione inhibits $\beta$-amyloid aggregation and protects damage from $\beta$-amyloid in SH-SY5Y cells. Neurochem Res 37: 622-628, 2012.

31. Ma L and Li W: Emodin inhibits LOVO colorectal cancer cell proliferation via the regulation of the Bcl-2/Bax ratio and cytochrome $c$. Exp Ther Med 8: 1225-1228, 2014.

32. Ricci JE, Gottlieb RA and Green DR: Caspase-mediated loss of mitochondrial function and generation of reactive oxygen species during apoptosis. J Cell Biol 160: 65-75, 2003.

33. Camilleri A, Zarb C, Caruana M, Ostermeier U, Ghio S, Högen T, Schmidt F, Giese A and Vassallo N: Mitochondrial membrane permeabilisation by amyloid aggregates and protection by polyphenols. Biochim Biophys Acta 1828: 2532-2543, 2013.

34. Wang X, Wang W, Li L, Perry G, Lee HG and Zhu X: Oxidative stress and mitochondrial dysfunction in Alzheimer's disease. Biochim Biophys Acta 1842: 1240-1247, 2014.

35. Santos RX, Correia SC, Wang X, Perry G, Smith MA, Moreira PI and Zhu X: Alzheimer's disease: Diverse aspects of mitochondrial malfunctioning. Int J Clin Exp Pathol 3: 570-581, 2010.

36. García-Escudero V, Martín-Maestro P, Perry G and Avila J: Deconstructing mitochondrial dysfunction in Alzheimer disease. Oxid Med Cell Longev 2013: 162152, 2013.

37. Swerdlow RH, Burns JM and Khan SM: The Alzheimer's disease mitochondrial cascade hypothesis: Progress and perspectives. Biochim Biophys Acta 1842: 1219-1231, 2014.

38. Cadonic C, Sabbir MG and Albensi BC: Mechanisms of mitochondrial dysfunction in Alzheimer's disease. Mol Neurobiol 53 6078-6090, 2016

39. Rhein V, Song X, Wiesner A, Ittner LM, Baysang G, Meier F, Ozmen L, Bluethmann H, Dröse S, Brandt U, et al: Amyloid- $\beta$ and tau synergistically impair the oxidative phosphorylation system in triple transgenic Alzheimer's disease mice. Proc Natl Acad Sci USA 106: 20057-20062, 2009.

40. Gottlieb E, Armour SM, Harris MH and Thompson CB: Mitochondrial membrane potential regulates matrix configuration and cytochrome $c$ release during apoptosis. Cell Death Differ 10: 709-717, 2003.

41. Hansson Petersen CA, Alikhani N, Behbahani H, Wiehager B, Pavlov PF, Alafuzoff I, Leinonen V, Ito A, Winblad B, Glaser E, et al: The amyloid beta-peptide is imported into mitochondria via the TOM import machinery and localized to mitochondrial cristae. Proc Natl Acad Sci USA 105: 13145-13150, 2008.

42. Picone P, Nuzzo D, Caruana L, Scafidi V and Di Carlo M: Mitochondrial dysfunction: Different routes to Alzheimer's disease therapy. Oxid Med Cell Longev 2014: 780179, 2014. 